\title{
The influence of linguistic acculturation and parental monitoring on the substance use of Mexican-heritage adolescents in predominantly Mexican enclaves of the Southwest US
}

\author{
Flavio F. Marsiglia, Ph.D. ${ }^{1,2}$, Julie L. Nagoshi, Ph.D. ${ }^{1,2}$, Monica Parsai, Ph.D. ${ }^{1,2}$, and Felipe \\ González Castro, Ph.D. ${ }^{1,3}$ \\ ${ }^{1}$ Southwest Interdisciplinary Research Center, Arizona State University \\ ${ }^{2}$ School of Social Work, Arizona State University \\ ${ }^{3}$ Department of Psychology, Arizona State University
}

\section{Abstract}

This study presents the results of an assessment of 377 Mexican heritage $7^{\text {th }}$ grade adolescents attending middle school in Arizona. The students answered questions concerning personal substance use, linguistic acculturation and parental monitoring. Linguistic acculturation in general did not predict substance use, while greater perceived parental monitoring significantly predicted a lesser likelihood to use substances for both boys and girls. There was a significant acculturation by parental monitoring interaction for ever use of alcohol for boys, with parent monitoring effects being more pronounced in reducing alcohol use among highly acculturated boys. Results are discussed in terms of how acculturation impacts family processes and the drug use behaviors of Mexican heritage adolescents living in predominantly Mexican enclaves.

\section{INTRODUCTION}

Latino adolescents constitute a very heterogeneous group. Latino is an umbrella label that encompasses youths of different national origins, levels of acculturation, socioeconomic status, migration history and many other contextual factors, such as place of residence within the U.S. (Berry, 2006; Portes \& Rumbaut, 2001; Wahl \& Eitle, 2010). A focus on Mexican heritage youth is important because they are the largest Latino adolescent subgroup in the U.S. (U.S. Census, 2008).

Latino youth consistently report higher use rates of alcohol and other drugs than youth of other ethnic backgrounds. Eighth grade Latinos report more alcohol and illicit drug use (with the exception of amphetamines) than their White non-Hispanic counterparts (Johnston, O'Malley, Bachman, \& Schulenberg, 2011). By the time Latino students reach the 12th grade, their use of both alcohol and other drugs is lower than the use rates of their White non-Hispanic classmates (Johnston et al., 2011). These lower use rates need to be interpreted with caution because approximately $40 \%$ of Hispanic adolescents drop out of high school (Greene \& Forster, 2003); many senior age Latino students are therefore not represented in existing school-based national epidemiological trends. These substance use rates, however, also need to be considered in the context of acculturation. For example, first generation Latino immigrant youth, including Mexicans, reported lower alcohol use rates (6.3\%) than

Contract Information: Dr. Flavio F. Marsiglia, Southwest Interdisciplinary Research Center, School of Social Work, Arizona State University, Marsiglia@asu.edu. 
second generation (11.6\%) or third (7.5\%) generation youth in the Add Health probability study (Hussey et al., 2007).

The present article reports the results of a study of Mexican heritage adolescents' perceptions of their parents' monitoring of their behaviors and the relationship of the perceived parental monitoring to the youth's substance use behaviors for a sample of middle school youth drawn from ethnically homogeneous neighborhoods. This relationship is considered in the context of the adolescents' level of linguistic acculturation. Since Mexican heritage families in the traditional Mexican areas of the U.S. experience high levels of housing segregation, the present study questions the applicability of traditional acculturation theory in researching the experiences of acculturating Mexican heritage youth. When adolescents live in majority Mexican neighborhoods and attend majority Mexican schools, what are they acculturating to? These youths are at a stage of development when the influence of family is still strong (Tobler \& Komro, 2010), and the present study aims at sorting the different influences of acculturation and family on alcohol and other drug use behaviors in these youth.

\section{Parental monitoring and substance use}

Parental monitoring may be defined as the extent to which parents watch, supervise, and stay aware of their children's day to day activities (Bahr et al., 1998). Parents who effectively monitor their adolescents have children who are at lower risk of smoking, drinking, and using illegal substances than the average teen (CASA, 2001). Parental monitoring has been found to decrease the likelihood of substance use among adolescents and to increases the youth's likelihood to choose friends who are not substance users (Thorlindsson \& Bernburg, 2006). There is strong evidence supporting the important role parents play in preventing drug use during early adolescence and existing findings support the involvement of parents and the strengthening of parental monitoring and communication skills as fruitful targets for the prevention of problem behaviors (Tobler \& Komro, 2010).

On the other hand, adolescents whose parents are lax about behavioral standards and have few guidelines for their children (Sargent \& Dalton, 2001) have been found to engage in increased rates of substance use and other antisocial behaviors (Marsiglia \& Waller, 2002; Mounts, 2001; Parsai, Marsiglia, \& Kulis, 2010; Wood et al., 2004). Low parental monitoring and highly permissive parenting have also been associated with children's poor academic performance in school and involvement in delinquency (Shumow, Vandell, \& Posner, 1998), such as substance use (Barnes, Reifman, Farrell, \& Dintcheff, 2000; Komro \&Toomey, 2002).

Parental influences, such as parental monitoring and parental permissiveness, may differ across ethnic groups because they are shaped by culture-specific norms and by ecological factors, such as acculturation (Voisine, Parsai, Marsiglia, Kulis, \& Nieri, 2008). This is of particular relevance in the Southwest, a region experiencing an increasingly high rate of immigration. In Mexican heritage families, researchers have identified familismo, or family strength, as a core cultural component and as a strong factor against youth substance use (Holleran \& Waller, 2003; Marsiglia, Parsai, \& Kulis, 2009; Marsiglia \& Waller, 2002). The value of family-centeredness and familismo includes support, counseling, advice, modeling behavior, and close monitoring of the children's activities and relationships (Voisine, et al, 2008). Familismo can be seen as a protective factor and is thought to buffer the effects of acculturation stress experienced by adolescents (Balls Organista, Organista, \& Kurasaki, 2003; Marsiglia \& Waller, 2002). 


\section{Acculturation and substance use}

Acculturation has been defined as an ongoing process through which people from one culture adjust to another culture, modifying their attitudes and their behaviors as a result of the contact with the new culture (Berry, 1970). Studies of acculturation among different populations have demonstrated both the importance of language and its integral impact on learning, culture, and socialization (Heath, 1983; Ochs, 1988). Non-English speaking immigrant children learn English through involvement in social interactions, thereby constructing identities, beliefs, and cultural symbols in ways that vary distinctly from native children (Alvesson \& Karreman, 2000).

The use of English by Mexican immigrants in the United States has often been used as a measure of acculturation because English language fluency affects the ability to interact and communicate with the majority culture (Unger, Ritt-Olsen, Wagner, Soto, \& BaezcondeGarbanati, 2007). Although language is a unidimensional indicator of acculturation, previous studies have found that English language use is comparable to multi-dimensional measures, accounting for approximately $65 \%$ of the variance in acculturation status (Epstein et al., 2001; Samaniego \& Gonzales, 1999; Serrano \& Anderson, 2003).

Studies of acculturation among different populations have demonstrated its significant impact on both psychological and behavioral changes (Berry, 1970; Witkin \& Berry, 1975). Higher acculturation among Mexican American groups has been linked to an increase in substance use and dependence (Epstein et al., 2001). Studies in different regions of the United States show that Mexican youth who use Spanish at home report significantly less substance use than students who speak English with their parents. Bilingual youth have also been found to be at a somewhat greater risk of substance use than monolingual Spanish speaking students (Epstein et al., 2001; Marsiglia \& Waller, 2002).

English language acquisition can operate as a risk factor for some Mexican heritage youth, and the reasons for this negative effect are varied (Marsiglia et al., 2010). First, it may introduce and reinforce behaviors of the mainstream culture, causing value conflicts with the culture of origin (Gilbert \& Cervantes, 1986; Vega et al., 1997). Second, English language acquisition may increase stress, as the individual attempts to resolve conflicting cultural differences, leading to negative attempts to reduce stress through drug use (Beauvais, 1998; Gil \& Wagner, 2000). And lastly, English language acquisition increases one's familiarity with the new host culture, which may facilitate the learning of the pro-drug norms of the host culture. For example,Marsiglia et al. (2010) found that the linguistic acculturation status of a sample of Mexican heritage middle school students in the Southwest was found to be positively and directly related to their adherence to pro-drug norms, substance use intentions, and recent alcohol use with the direct effect of linguistic acculturation on prodrug norms being stronger for girls than for boys.

\section{Parental monitoring, acculturation, and substance use}

Several explanations can be offered for possible connections among parental monitoring, linguistic acculturation, and substance use (Marsiglia et al., 2010). Due to contact with majority culture systems, such as schools, children of immigrants tend to learn English faster than adults (Marsiglia, Miles, Dustman, \& Sills, 2003; Rogler, Cortes, \& Malgady, 1991). The acquisition of and preference for English by children in non-English proficient families has been identified as a main source of erosion of family communication and protective ties, such as parental monitoring. Spanish language dominance appears to protect adolescents by sheltering them from an expansion of their social networks that puts them at a greater risk for encountering pro-drug peers and opportunities to use substances (Escobar, 1998). English language acquisition, in contrast, enables adolescents to access the broader English 
speaking community and enter new situations and access new peer networks, where substances are offered, while ultimately distancing them from the protective effects of family and culture of origin (Chilcoat, Breslau, \& Anthony, 1996; Flannery, Williams, \& Vazsonyi, 1999).

Meanwhile, the social reinforcement that occurs through continued Spanish language usage can help to preserve certain aspects of traditional Mexican culture that may be protective against drug use, including familismo, which emphasizes the importance on the family of origin and strengthens family pride, respect for parents, and family closeness, trust, and cohesion (Castro et al., 2006; Castro \& Gutierres, 1997; Chandler, Tsai, \& Wharton, 1999; Suarez-Orozco \& Suarez-Orozco, 1995). This family value is often associated with greater parental monitoring and involvement with children (Castro \& Hernández-Alarcón, 2002; Chandler, Tsai, \& Wharton, 1999; Denner, Kirby, \& Coyle, 2001), which can protect against substance use (Duncan et al., 1998; Flannery et al., 1999).

It might thus be expected that the effect of parental monitoring on substance use in Mexican American adolescents may be mediated by acculturation or the effect of acculturation on substance use mediated by parental monitoring, as acculturation acts to erode parental monitoring. Fridrich and Flannery's (1995) study of Mexican American and Caucasian early adolescents, however, found that the relationship between parental monitoring and delinquency was mediated by susceptibility to antisocial peer pressure, regardless of ethnicity or acculturation.Pokhrel et al. (2008) found no support for parent monitoring mediating the effect of acculturation on alcohol use in their sample of Hispanic adolescents. Ramirez et al.'s (2004) study of Anglo and Hispanic American adolescents found that parental monitoring and acculturation both had significant independent effects on predicting substance use. On the other hand, Warner et al.'s (2010) study of Mexican American adolescents found no effects of several indices of acculturation with alcohol use while a brief self-report measure of parent involvement/ communication did not significantly predict alcohol use.

An alternative hypothesis is that acculturation moderates the effects of parental monitoring, such that parental monitoring effects are attenuated only for highly acculturated Mexican American youth, where the values of familismo and parent-youth communication and closeness have been eroded by the youth's greater identification with U.S. culture. In theRamirez et al. (2004) study noted above, a significant familism by parental monitoring interaction was found for inhalant use, where parental monitoring effects were stronger for adolescents with stronger familism, but the acculturation by parental monitoring interactions were not significant.

\section{Hypotheses}

We thus propose the following hypotheses in the present study:

Hypothesis 1. Among Mexican-heritage youth, higher levels of linguistic acculturation will be associated with higher rates of substance use.

Hypothesis 2. Conversely, higher levels of perceived parental monitoring will be associated with lower rates of substance use.

Hypothesis 3. Linguistic acculturation will operate as a moderator of the effect of parental monitoring on levels of substance use. Therefore, a significant interaction effect is expected in which the positive effects of parental monitoring in promoting lower levels of substance use will be attenuated by higher levels of linguistic acculturation. 


\section{Methods}

\section{Sample}

The data analyzed here come from a longitudinal study of the effectiveness of a Parent Education supplement (PIs: Drs. Felipe Castro and Flavio Marsiglia at Arizona State University) to the established keepin' it REAL (Marsiglia \& Hecht, 2005) primary prevention intervention for adolescent substance use. Data for the present analyses come from the pre-intervention Wave 1 assessment of 388 (189 boys, 204 girls, 3 missing gender) $7^{\text {th }}$ grade participants recruited from 9 local Phoenix area schools from two school districts with heavily Mexican heritage populations. Analyses are presented for those 347 participants (162 boys, 182 girls, 3 missing gender) who indicated their ethnicity as being Mexican, Mexican American, or other Latino. The mean age of this sample was 12.25 years $(\mathrm{SD}=.50)$ at the time of initial testing.

\section{Measures}

Substance use was measured by questions related to amount and frequency of lifetime and recent use of alcohol, cigarettes, marijuana, or inhalants. These questions were modeled after questions previously used by Flannery, Williams, and Vazsonyi (1999) and were chosen for their developmental appropriateness for the age group under study, and their successful use with a Mexican-heritage youth population (Kulis, Marsiglia, Elek, Dustman, Wagstaff, \& Hecht, 2005). Results are presented only for ever use of substances, due to the low frequencies of use and high positive skews of the quantitative use measures.

Control variables included age, school grades, and whether the student was receiving the Federal school lunch program.

Acculturation was measured by the Linguistic Acculturation scale (Marin et al., 1987), a composite of three items ( $\alpha=.67$ for the present sample) asking whether English use is preferred over non-English in language use with family, friends, and media (TV, radio, music). Responses were on a 5-point scale ranging from $1=$ "English only" to $5=$ "Spanish only," with scale scores being the mean across the items reverse-coded, so that higher scores represent more acculturation. Linguistic acculturation has been justified as a useful indicator of acculturation in studies of the relationship of acculturation with other behaviors (Epstein et al., 2001, Marsiglia et al., 2010).

Parental Monitoring was a measured by a 5-item scale $(\alpha=.79)$ adapted from Kerr and Stattin (2000) and Stattin \& Kerr (2000) that asks about whether parents know what the child is doing in their free time and after school, who their friends are, where they're going when they leave the house, and what time they'll be back. Items were responded to on 4point scales ranging from $1=$ "always" to $4=$ "never," with scale scores being the mean across the items reverse-coded, so that higher scores represent more youth's perceived parental monitoring. Adolescents' perceptions of the degree in which their parents monitor their behavior in relationship to alcohol and other drugs has been found to be significantly correlated with the actual monitoring reported by the parents themselves (Pasch, Stigler, Perry, \& Komro, 2010).

\section{Analyses}

Hierarchical multiple regression analyses were conducted to predict any lifetime use of alcohol, cigarettes, marijuana, or inhalants, with models being run separately by gender. The first block of the model included the control variables, the second block added linguistic acculturation, the third block entered parental monitoring, and the final block entered the interaction of linguistic acculturation by parental monitoring. The interaction term was 
computed by centering the acculturation and parental monitoring scores and then multiplying the centered terms. It should be noted that the results were essentially the same when these analyses were run as logistic regressions.

\section{Results}

For the ever used substances variables, 40.1 percent of the sample reported having used alcohol, 10.4 percent had used cigarettes, 10.1 percent had used marijuana, and 8.1 percent had used inhalants.

Table 1 presents the means and standard deviations for the control variables, linguistic acculturation, parental monitoring, and ever use of alcohol, cigarettes, marijuana, or inhalants separately by sex. There were no significant sex differences on these variables.

The correlation between linguistic acculturation and parental monitoring was $.18(\mathrm{p}<.05)$ for boys, but only -.02 (n.s.) for girls. Table 2 present the correlations of linguistic acculturation and parental monitoring with the substance use measures separately by gender. In general, linguistic acculturation was uncorrelated with substance use, with the exception of alcohol use in boys, which is surprisingly negative, while parental monitoring was consistently significantly negatively correlated with substance use for both boys and girls.

Table 3 presents the hierarchical multiple regression results for ever use of alcohol, cigarettes, marijuana, or inhalants for the four-block model including 1) control variables (not reported in the table, but included in the analyses), 2) linguistic acculturation, 3) parental monitoring, and 4) the interaction of linguistic acculturation measure by parental monitoring separately for boys and girls. In general, the acculturation and parental monitoring main effects were not affected by the addition of the interaction terms, so the betas for the full model are presented. In general, linguistic acculturation did not predict substance use, while greater parental monitoring significantly predicted lower substance use over and above the control variables and acculturation for most of the substance use variables for both boys and girls. For boys, there was a significant interaction of linguistic acculturation by parental monitoring for ever use of alcohol (betas for low and high acculturation groups were .01 and -.41, respectively; Figure 1), indicating that parental monitoring effects were most pronounced in reducing alcohol use in the most highly acculturated boys. A hierarchical multiple regression analysis was conducted on the full sample to test the 3-way interaction of sex by linguistic acculturation by parental monitoring in predicting alcohol use, and the addition of the 3-way interaction term was found to be significant $\left(\mathrm{r}^{2}\right.$ change $=.015, \mathrm{~F}$ change $\left.=5.167, \mathrm{p}<.05\right)$. In the present sample of Mexican American adolescents from ethnic enclaves, the continued significant effects of parental monitoring on substance use, even after controlling for the effect of linguistic acculturation, as well as the significant linguistic acculturation by parental monitoring effect on alcohol use in boys, are all inconsistent with the theory that the effects of acculturation on substance use are mediated by correlated changes in parenting effects.

\section{Discussion}

The present findings suggest that acculturation and parental monitoring effects on substance use in Mexican heritage adolescents residing in ethnic enclaves may operate through different mechanisms than those found for Mexican heritage adolescents residing in more ethnically diverse neighborhoods. The direct effects of linguistic acculturation were only minimally related to the substance use of these adolescents, but acculturation did have an indirect effect through moderating the influence of parental monitoring. 
Only partially consistent with Hypothesis 1, adolescent Mexican American boys experiencing higher levels of linguistic acculturation reported higher levels of alcohol use. Hypothesis 2 was confirmed in that youths reporting higher levels of parental monitoring reported lower alcohol and other drug use rates. As proposed in Hypothesis 3, linguistic acculturation moderated the effects of parental monitoring on alcohol use in boys, a finding which advances new knowledge about the relationships among acculturation, parenting, and substance use in Mexican heritage adolescents who reside within ethnically homogeneous Mexican enclaves . The direction of the effects, however, were not expected, with parental monitoring having a stronger negative relationship with alcohol use for boys who were high in linguistic acculturation.

The present findings suggest the need to consider gender differences that are linked to Mexican cultural traditions (Marsiglia et al., 2010b). Residence within an ethnic enclave exposes youths to traditional Mexican culture protective norms (Castro et al., 2006), including gendered expectations imposed upon Mexican-heritage females. These normative expectations emphasize sheltering females against risk conditions, including restrictive parental monitoring that is directed towards young females (Medina-Mora \& Rojas-Guiot, 2003). As girls coming from traditional Mexican homes acquire the English language and become exposed to unsupervised bilingual or English monolingual social networks outside of their neighborhood, their level of risk for the use and abuse of alcohol, tobacco and other drugs may increase. In this regard, more acculturated Mexican-heritage girls may become more vulnerable to drug use offers and to actual use, when compared with their less acculturated Mexican peers. Furthermore, Mexican girls may be at even greater risk than Mexican boys of the same level of linguistic acculturation, in part due to Mexican females' lack of experience with risky situations (Marsiglia et al., 2010).

The fact that the interaction found in the present study appeared only for alcohol use may reflect the more permissive Mexican cultural norms involving alcohol use that exist for boys within the Mexican culture (Kulis, Marsiglia, \& Nagoshi, 2010; in press). In Mexican culture, the traditional masculine gender role expectations of machismo and celebratory fiesta drinking emphasize binge drinking (Caetano \& Medina-Mora, 1988), along with the ability to consume high levels of alcohol without losing one's self-control (Loury \& Kulbok, 2007). The negative correlation observed in the present study between linguistic acculturation and alcohol use for this sample of Mexican American boys from an ethnic enclave, contrasts with previous findings from prior studies that report a positive correlation between acculturation and drug use (e.g., Epstein et al., 2001) and may reflect this adherence to traditional masculine norms for heavy alcohol use. The acculturation by parental monitoring interaction seems to indicate that parental monitoring is especially effective when boys are further along in the acculturation process, when these traditional cultural norms are less likely to override parental norms. Among low-acculturated Mexican-heritage boys, these cultural norms may also lower the need for a very proactive or explicit parental monitoring, as the community plays a monitoring role.

Understanding the potential protective role that living in an ethnic enclave may have against the negative effects of acculturation may also require a consideration of how different forms of cultural adaptations operate. Bicultural (integrated) adolescents, as compared with assimilated or segregated adolescents, seem to be more protected against problem behaviors (Marsiglia, Parsai, \& Kulis, 2009). Bilingual/bicultural youths who are able to successfully adapt to both the Mexican and the American cultures (Castro, Boyer, \& Balcazar, 2000), and can easily shuttle from one culture to the other (cultural flex) may benefit from the attitudes, values and skills that are acquired from both cultures (Feliciano, 2001). 
From a family resiliency perspective, among Mexican-heritage youths, biculturalism and cultural flex may be a bicultural skill that enables these youth to retain the protective factors acquired from family and culture of origin (the Mexican culture), while also incorporating aspects of the new host culture (the American culture) new skills that help them and their families to better function within their new environment (Berry, 2006). The present findings appear to support previous research regarding the protective effects of bilingualism and biculturalism as an effective strategy to maintain the skills and norms from culture of origin and adolescents acquire new skills from the new culture (Sullivan, 2007).

\section{Limitations and implications for future research}

The data used in this study come from surveys collected by a randomized intervention study being conducted with youth residing in predominantly Mexican neighborhoods in a large Southwestern city and may not be representative of all Mexican heritage youths. Future research should include a larger size sample and a longitudinal design that allows for making inferences of temporal effects, along with the ability to see if the moderating effects of linguistic acculturation by parental monitoring change over time. A sampling strategy that explicitly recruited Mexican heritage adolescents from ethnically homogeneous enclaves versus those from ethnically heterogeneous neighborhoods would also be important to confirm the interpretations of the present findings. Additional measures of acculturation such as generation status, time of residence within the U.S, ethnic identification, and acculturation strategies should also be considered in the context of an ecological perspective within future studies.

\section{Acknowledgments}

This study was funded by the National Institute on Minority Health and Health Disparities (NIMHD) of the National Institutes of Health (NIH) (P20MD002316-0003-04, PI: Felipe González Castro) under the Exploratory Center of Excellence award (P20MD002316-04, PI: Flavio F. Marsiglia) funding the Southwest Interdisciplinary Research Center. This study was also funded by the National Institute on Drug Abuse (NIDA) of the National Institutes of Health (NIH) (F31 DA005629, PI: Julie Nagoshi). The content is solely the responsibility of the authors and does not necessarily represent the official views the NIMHD, NIDA, or the NIH.

\section{References}

Alvesson M, Karreman D. Taking the linguistic turn: Challenges, responses, consequences. The Journal of Applied Behavioral Science. 2000; 36:136-158.

Balls Organista, P.; Organista, KC.; Kurasaki, K. Acculturation among ethnic minority families. In: Chun, KM.; Balls Organista, P.; Marin, F., editors. Acculturation: Advances in theory, measurement, and applied research. Washington, DC: American Psychological Association; 2003. p. 95-119.

Bahr SJ, Maughan SL, Marcos A, Li B. Family, religiosity, and the risk of adolescent drug use. Journal of Marriage and the Family. 1998; 60(4):979-993.

Barnes GM, Reifman A, Farrell MP, Dintcheff B. The effects of parenting on the development of adolescent alcohol misuse: A six-wave latent growth model. Journal of Marriage and the Family. 2000; 62:175-186.

Berry JW. Marginality, stress, and ethnic identification in an acculturated Aboriginal community. Journal of Cross-Cultural Psychology. 1970; 1:17-22.

Berry, JW. Immigrant youth in cultural transition :Acculturation, identity, and adaptation across national contexts. Mahwah, NJ: Erlbaum; 2006.

Beauvais F. Cultural identification and substance use in North America: An annotated bibliography. Substance Use and Misuse. 1998; 33:1315-1336. [PubMed: 9603273]

Caetano R, Medina-Mora ME. Acculturation and drinking among persons of Mexican descent in Mexico and in the United States. Journal of Studies on Alcohol. 1988; 49:462-471. [PubMed: 3216651] 
CASA. [accessed October 2007] 2001. available online at www.casacolumbia.org/

Castro, FG.; Boyer, GR.; Balcazar, HG. Healthy adjustment in Mexican American and other Latino adolescents. In: Montemayor, R.; Adams, GR.; Gullotta, TP., editors. Adolescent diversity in ethnic, economic and cultural contexts. Thousand Oaks, CA: Sage; 2000. p. 141-178.

Castro FG, Garfinkle J, Naranjo D, Rollins M, Brook JS, Brook D. Cultural traditions as protective factors among Latino children of illicit drug users. Substance Use and Misuse. 2006; 42:621-642. [PubMed: 17558954]

Castro, FG.; Gutierres, S. Drug and alcohol use among rural Mexican Americans. In: Robertson, ER.; Sloboda, Z.; Boyd, GM.; Beatty, L.; Kozel, NJ., editors. Rural substance abuse: State of knowledge and issues. Rockville, MD: National Institute on Drug Abuse; 1997. p. 499-533.NIDA Research Monograph No. 168

Castro FG, Hernández-Alarcón E. Integrating cultural variables into drug abuse prevention and treatment with racial/ethnic minorities. Journal of Drug Issues. 2002; 32:783-810.

Chandler CR, Tsai TM, Wharton R. Twenty years after: Replicating a study of Anglo and Mexican American cultural values. Social Science Journal. 1999; 36:353-367.

Chilcoat HD, Breslau N, Anthony JC. Potential barriers to parent monitoring: Social disadvantage, marital status, and maternal psychiatric disorder. Journal of the American Academy of Child and Adolescent Psychiatry. 1996; 35:1673-1682. [PubMed: 8973075]

Denner J, Kirby D, Coyle K. The protective role of social capital and cultural norms in Latino communities: A study of adolescent births. Hispanic Journal of Behavioral Sciences. 2001; 23:321.

Duncan SC, Duncan TE, Biglan A, Ary D. Contributions of the social context to the development of adolescent substance use: A multivariate latent growth modeling approach. Drug and Alcohol Dependence. 1998; 50:57-71. [PubMed: 9589273]

Epstein JA, Botvin GJ, Diaz T. Linguistic acculturation associated with higher marijuana and polydrug use among Hispanic adolescents. Substance Use \& Misuse. 2001; 6:477-499. [PubMed: $11346278]$

Escobar JI. Immigration and mental health: Why are immigrants better off? Archives of General Psychiatry. 1998; 55:781-782. [PubMed: 9736003]

Feliciano C. The benefits of biculturalism: exposure to immigrant culture and dropping out of school among Asian and Latino youths. Social Science Quarterly. 2001; 82(4):865-880.

Flannery DJ, Williams LL, Vazsonyi AT. Who are they with and what are they doing? Delinquent behavior, substance use, and early adolescents' after-school time. American Journal of Orthopsychiatry. 1999; 69:247-253. [PubMed: 10234390]

Gil AG, Wagner EF. Acculturation, familism, and alcohol use among Latino adolescent males: Longitudinal relations. Journal of Community Psychology. 2000; 28:443-458.

Gilbert MJ, Cervantes RC. Patterns and practices of alcohol use among Mexican Americans: A comprehensive review. Hispanic Journal of Behavioral Sciences. 1986; 8:1-60.

Greene, JP.; Forster, G. Public high school graduation rates and college readiness rates in the United States. Manhattan, NY: Manhattan Institute for Policy research; 2003.

Heath, SB. Ways with words: Language, life and work in communities and classrooms. Cambridge: Cambridge University Press; 1983.

Holleran LK, Waller MA. Sources of resilience among Chicano/a youth: Forging identities in the borderlands. Child and Adolescent Social Work Journal. 2003; 20(5):335-350.

Hussey JM, Hallfors DD, Waller MW, Iritani BJ, Halpern CT, Bauer DJ. Sexual behavior and drug use among Asian and Latino adolescents: Association with immigrant status. Journal of Immigrant and Minority Health. 2007; 9:85-94. [PubMed: 17111214]

Johnston, LD.; O’Malley, PM.; Bachman, JG.; Schulenberg, JE. Monitoring the Future national results on adolescent drug use: Overview of key findings, 2010. Ann Arbor: Institute for Social Research, The University of Michigan; 2011.

Kerr M, Stattin H. What parents know, how they know it, and several forms of adolescent adjustment: Further support for a reinterpretation of monitoring. Developmental Psychology. 2000; 36:366380. [PubMed: 10830980] 
Komro KA, Toomey TL. Strategies to prevent underage drinking. Alcohol Research \& Health. 2002; 26(1):5-15. [PubMed: 12154652]

Kulis S, Marsiglia FF, Elek E, Dustman P, Wagstaff DA, Hecht ML. Mexican/Mexican American adolescents and keepin' it REAL: An evidence based substance abuse prevention program. Children \& Schools. 2005; 27:133-145. [PubMed: 21359122]

Kulis S, Marsiglia FF, Nagoshi JL. Gender roles, externalizing behaviors, and substance use among Mexican American adolescents. Journal of Social Work Practice in the Addictions. 2010; 10:1-25.

Kulis S, Marsiglia FF, Nagoshi J. Gender roles and substance use among Mexican American adolescents: A relationship moderated by acculturation? Substance Use and Misuse. (in press).

Loury S, Kulbok P. Correlates of alcohol and tobacco use among Mexican immigrants in Rural North Carolina. Family Community Health. 2007; 30:247-256. [PubMed: 17563486]

Marin G, Sabogal R, Marin BV, Otero-Sabogal R, Perez-Stable EJ. Development of a short acculturation scale for Hispanics. Hispanic Journal of Behavioral Science. 1987; 9:183-305.

Marsiglia, FF.; Hecht, ML. keepin' it REAL: An evidence-based program. Santa Cruz, CA: ETR Associates; 2005.

Marsiglia FF, Kulis S, Hussaini SK, Nieri T, Becerra D. Gender differences in the effect of linguistic acculturation on substance use among Mexican-Origin youth in the southwest United States. Journal of Ethnicity in Substance Use. 2010; 9:40-63.

Marsiglia FF, Miles BW, Dustman P, Sills S. Ties that protect: An ecological perspective on Latino/a urban pre-adolescent drug use. Journal of Ethnic and Cultural Diversity in Social Work. 2003; 11:191-220.

Marsiglia FF, Parsai MB, Kulis S. Effects of familism \& family cohesion on problem behaviors among adolescents in Mexican immigrant families in the Southwest U.S. Journal of Ethnicity \& Cultural Diversity in Social Work. 2009; 18:203-220.

Marsiglia FF, Waller M. Language preference and drug use among Southwestern Mexican American middle school students. Children \& Schools. 2002; 25(3):145-158.

Medina-Mora ME, Rojas Guiot E. Mujer, probeza, y adicciones. Perinatolgia y Reproduccion Humana. 2003; 17:230-244.

Mounts NS. Young adolescents' perceptions of parental management of peer relationships. Journal of Early Adolescence. 2001; 21:92-122.

Ochs, E. Culture and language development. New York: Cambridge University Press; 1988.

Parsai M, Marsiglia FF, Kulis S. Parental monitoring, religious involvement and drug use among Latino and Non-Latino youth in the southwestern United States. British Journal of Social Work. 2010; 40:100-114. [PubMed: 20046816]

Pasch KE, Stigler MH, Perry CL, Komro KA. Parents' and children's self-report of parenting factors: How much do they agree and which is more strongly associated with early adolescent alcohol use? Health Education Journal. 2010; 69:31-42. [PubMed: 20563227]

Pokhrel P, Unger JB, Wagner KD, Ritt-Olson A, Sussman S. Effects of parental monitoring, parentchild communication and parent's expectation of the child's acculturation on the substance use behaviors of urban Hispanic adolescents. Journal of Ethnicity in Substance Abuse. 2008; 7(2): 200-213. [PubMed: 19042806]

Portes, A.; Rumbaut, RG. Legacies. Berkeley: University of California Press; 2001.

Ramirez JR, Crano WD, Quist R, Burgoon M, Alvaro EM, Granpre J. Acculturation, familism, parental monitoring, and knowledge as predictors of marijuana and inhalant use in adolescents. Psychology of Addictive Behaviors. 2004; 18(1):3-11. [PubMed: 15008680]

Rogler LH, Cortes DE, Malgady RG. Acculturation and mental health status among Hispanics: Convergence and new directions for research. American Psychologist. 1991; 46:585-597. [PubMed: 1952420]

Samaniego R, Gonzalez N. Multiple mediators of the effects of acculturation status on delinquency for Mexican American adolescents. American Journal of Community Psychology. 1999; 27:189-210. [PubMed: 10425699]

Sargent J, Dalton M. Does parental disapproval of smoking prevent adolescents from becoming established smokers? Pediatrics. 2001; 108(6):1256-1262. [PubMed: 11731645] 
Schwartz SJ, Montgomery MJ, Briones E. The role of identity in acculturation among immigrant people: Theoretical propositions, empirical questions, and applied recommendations. Human Development. 2006; 49(1):1-30.

Serrano E, Anderson J. Assessment of a refined short acculturation scale for Latino preteens in rural Colorado. Hispanic Journal of Behavioral Sciences. 2003; 25:240-253.

Shumow L, Vandell DL, Posner JK. Harsh, firm, and permissive parenting in low-income families: Relations to children's academic achievement and behavioral adjustment. Journal of Family Issues. 1998; 19(5):483-508.

Stattin H, Kerr M. Parental monitoring: A reinterpretation. Child Development. 2000; 71:1072-1085. [PubMed: 11016567]

Suarez-Orozco, C.; Suarez-Orozco, M. Transformations: Immigration, family life, and achievement motivation among Latino adolescents. Stanford, CA: Stanford University Press; 1995.

Sullivan S, Schwartz SJ, Prado G, Huang S, Pantin H, Szapocznik J. A bidimensional model of acculturation for examining differences in family functioning and behavior problems in Hispanic immigrant adolescents. The Journal of Early Adolescence. 2007; 27(4):405-430.

Thorlindsson T, Bernburg JG. Peer groups and substance use: examining the direct and interactive effect of leisure activity. Adolescence. 2006; 41:321-339. [PubMed: 16981620]

Tobler AL, Komro KA. Trajectories of parental monitoring and communication and effects on drug use among urban young adolescents. Journal of Adolescent Health. 2010; 46:560-568. [PubMed: 20472213]

Unger JB, Ritt-Olson A, Wagner K, Soto D, Baezconde-Garbanati L. A comparison of acculturation measures among Hispanic/Latino adolescents. Journal of Youth and Adolescence. 2007; 36:555565.

US Census Bureau. 2008

Vega WA, Zimmerman RS, Warheit GJ, Apospori E, Gil AG. Acculturation strain theory: Its application in explaining drug use behavior among Cuban and other Hispanic youth. Substance Use \& Misuse. 1997; 32:1943-1948.

Voisine S, Parsai M, Marsiglia FF, Kulis S, Nieri T. Effects of parental monitoring, permissiveness, and injunctive norms on substance use among Mexican and Mexican American adolescents. 2008

Wahl A-MG, Eitle TM. Gender, acculturation and alcohol use among Latina/o adolescents: A multiethnic comparison. Journal of Immigrant Minority Health. 2010; 12:153-165.

Warner TB, Fishbein DH, Krebs CP. The risk of assimilating? Alcohol use among immigrant and U.S.-born Mexican youth. Social Science Research. 2010; 39:176-186. [PubMed: 20161417]

Witkin HA, Berry JW. Psychological differentiation in cross-cultural perspective. Journal of CrossCultural Psychology. 1975; 6:4-87.

Wood MD, Mitchell RE, Read JP, Brand NH. Do parents still matter? Parent and peer influences on alcohol involvement among recent high school graduates. Psychology of Addictive Behaviors. 2004; 18(1):19-30. [PubMed: 15008682] 


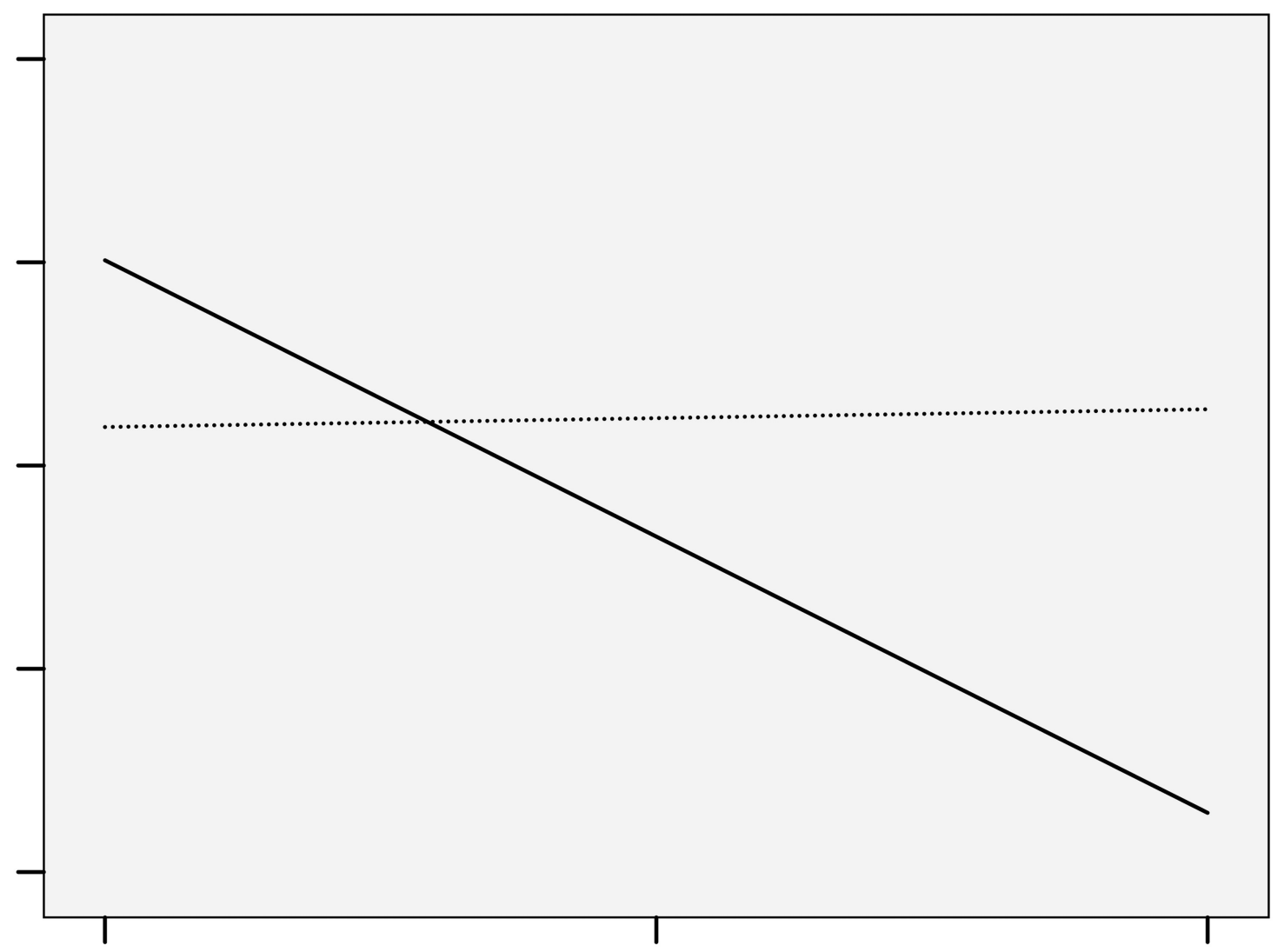

Figure 1.

Linguistic acculturation by parental monitoring interaction for alcohol use for boys. <AQ> labels needed for axes and legend? 


\section{Table 2}

Correlations of acculturation and parental monitoring with substance use

\begin{tabular}{lllll}
\hline & Alcohol & Cigarettes & Marijuana & Inhalants \\
\hline Males & & & & \\
Linguistic accult. & $-.21^{*}$ & -.13 & -.03 & .00 \\
Parental monitoring & $-.21^{*}$ & $-.28^{* * *}$ & $-.23^{* *}$ & -.08 \\
Females & & & & \\
Linguistic accult. & .04 & .05 & .08 & .00 \\
Parental monitoring & $-.23^{* *}$ & $-.15^{*}$ & $-.19^{*}$ & $-.35 * * *$ \\
\hline$*$ & & & & \\
$\mathrm{p}<.05$ & & & \\
$* *$ \\
$\mathrm{p}<.01$
\end{tabular}




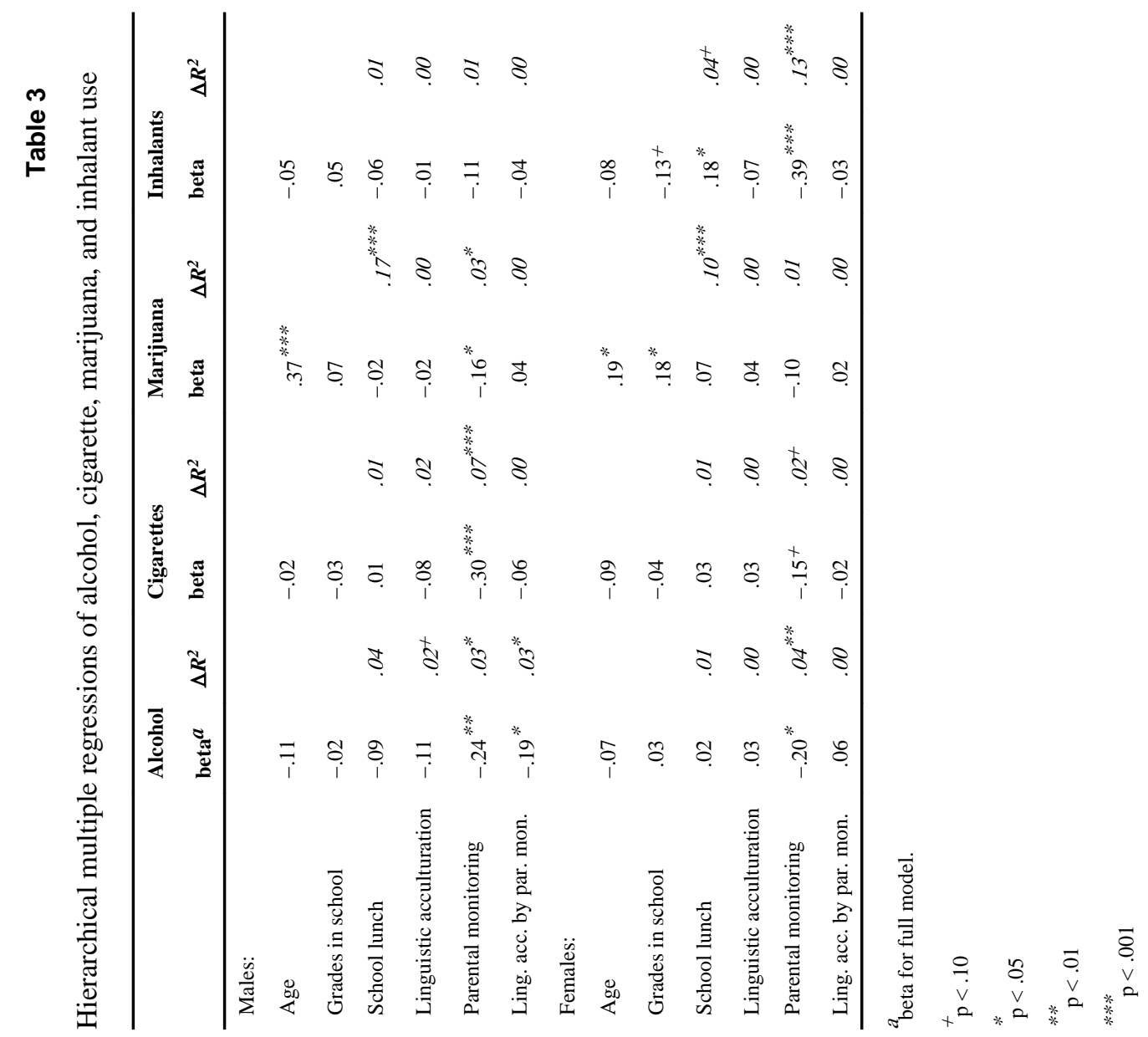

J Ethn Subst Abuse. Author manuscript; available in PMC 2013 July 01. 